\title{
Model for Simulating the Financial Viability of a Just-in-Time Maintenance Program in an Agribusiness Company

\author{
DOI:10.7595/management.fon.2021.0009
}

\section{Abstract:}

Research Question: The objective of this article is to present the model for simulating the financial viability of a Just-in-Time Maintenance Program in an agribusiness company. Motivation: Maintenance management in agro-industrial environments lacks effective systems to optimize the production process. The existing maintenance program have proven to be ineffective, from the point of view that unscheduled production downtime continues to occur. It is important to highlight that the types of maintenance used today, considering that their characteristics are not able to reduce or minimize the errors caused by human limited capacity, which has contributed to the increase of unscheduled production stoppages, causing equipment unavailability, low quality of final products and, mainly, failing to deliver products as agreed with customers. Idea: The maintenance program called Just-In-Time Maintenance Program - Maintenance Just in Time - consists of an integrated system for monitoring physical phenomena, with sensors installed in the equipment, connected to a central diagnosis able to predict failures in real time. With this program, it is possible to know in advance what may happen, taking the necessary measures regarding the acquisition of parts, repairs, and personnel allocation, among others, making these stops compatible or readjusting them with the production plan to minimize the undesirable stops. Data: The choice of the company participating in the research is made due to its continuous production process. The present study used a non-probabilistic sample for convenience with that provided by the observed company. The information collected in the agribusiness regarding the selling price, cost of raw material, cost of electricity, and total expenditure on maintenance, refer to the year 2020. Tools: A mathematical model was developed that estimates variations in the company's productivity and the consequent financial impacts. The results, operational and financial, of the model allow assessing the feasibility of implementing each of these programs. Findings: The results obtained indicate losses with the current maintenance program and show the potential for implementing the Just-In-Time Maintenance Program. This research concludes that it is possible to reduce unscheduled stoppages that cause production interruptions, increasing profit, with the implementation of the Just-In-Time Maintenance Program. Contribution: This article contributes to the literature as it presents an equipment maintenance model based on operational conditions, in contrast to other existing maintenance programs.

Keywords: Just-In-Time Maintenance Program, unexpected downtime, continuous production process, maintenance management.

JEL classification: L2, L23

\section{Introduction}

The manufacturing industry has experienced an unprecedented degree of change in the past three decades involving drastic changes in management, products, process technologies, customer expectations and supplier attitudes, as well as competition among the players involved in the value chain (Ahuja \& Khamba, 2008). Competition is in every corner of the world, and markets are quickly becoming more price sensitive. Achieving manufacturing excellence is seen as essential for the survival and economic growth for the whole country in this era of globalization (Singh \& Khanduja, 2010; Kaur, Singh \& Ahuja, 2013). 
Maintenance is not just to ensure the equipment condition in a facility, it also plays a crucial role in achieving the organization's goals and objectives, with the reduction of maintenance costs and the availability of equipment so that the production is able to produce what was planned (Velmurugan \& Dhingra, 2015; Teixeira, Lopes \& Braga, 2020; Ruschel, Santos \& Loures, 2017).

The observed company has a continuous production process, and any unexpected stoppage will result in production interruptions. The types of maintenance first presented will be as follows: scheduled, preventive, predictive, and productive, along with their characteristics, all based on equipment usage time, i.e., MTB Maintenance Time Based. An analysis is also carried out, identifying the potential economic advantage for the company, from the implementation of Just-in-Time Maintenance, leading to an increase in quality and productivity, a reduction in unforeseen downtime, avoiding delays in the delivery of products and consequently the increase in operating profit. The aim of the paper is to present the model for simulating the financial viability of a Just-In-Time Maintenance Program in an agribusiness company.

The article is divided into six sections. The first section is the Introduction. In the second section, the literature review is presented, providing information about the existing maintenance programs. The third section presents the methodological path. In the fourth section, the simulation of the implementation of Just-In-Time Maintenance Program in a company in the agribusiness sector is demonstrated. In the fifth section there is a presentation of the results and, finally, the final considerations are offered in the sixth section.

\section{Literature Review}

\subsection{Scheduled maintenance}

Scheduled maintenance is a type of maintenance that has shown, not at low frequency, failures in the downtime forecast due to the estimates of equipment lifetime and its components being carried out through probabilities. The philosophy behind scheduled maintenance is to fix it before it fails, thus maintenance is carried out before the equipment enters a failure state (Jimenez, Bouhmala \& Gausdal, 2020). The probabilities most of the time do not coincide with reality, and downtime may happen before the scheduled deadlines, as well as afterwards. In this way, maintenance stops occur at the most likely times, without knowing the moment when the failure will occur. Scheduled maintenance acts more like a safety measure seeking to reduce losses. That is why it is not enough to make up for equipment failures.

The increase in the cost of purchasing components, the need for repairs out of season, the disruption of normal routine activities and the stoppage of production, generate a drop in revenue, which will be converted into losses, attributed as a cause of maintenance based on probabilities or equipment lifetime. With the occurrence of stops, the cost of production rises. Productivity decreases according to the rate of equipment usage, so it is necessary to develop a maintenance type capable of avoiding such occurrences.

The difficulty found in companies as regards solving their problems with equipment maintenance has been crucial. In absolute terms, maintenance costs force many companies to re-analyze the role of maintenance in the impact of profitability, efficiency, and competitiveness (De Marco \& Mangano, 2011). The lack of criteria when choosing maintenance programs, the use of records that would allow a historical survey of all maintenance equipment and components, problems with the replacement of parts, and the lack of parts in stock may cause even more damage to the system adopted, the scheduled maintenance. Maintenance of industrial equipment has been a topic of growing discussion in the business environment. The purchase of new equipment is increasingly unfeasible, mainly due to the high cost of new technologies; proper care of the equipment has become very important (Bartz, Siluk \& Bartz, 2014).

All scheduled maintenance is based on time, i.e., maintenance based on the lifetime of parts. In order to avoid or minimize problems with unscheduled production downtime, industries seek to follow manufacturers' specifications regarding parts replacement. Two situations should be considered in time-based maintenance: the first is in relation to the replacement of the part, even without the need; the part is in good condition, however, on the manufacturer's recommendation, it must be replaced. Second, this part could be used even longer, but as a precaution, it will be replaced. Just-In-Time Maintenance Program is a system based on the equipment's operating conditions. Using sensors attached to the equipment, the Diagnosis Center receives information in real time, assessing whether or not the parts replacement is necessary. The Just-In-Time Maintenance Program's advantage is to have the part replaced at the right time, neither before nor after, which is similar to what happens in the Scheduled Maintenance. 


\subsection{Preventive maintenance}

Repairing the equipment after it fails may not always be the best maintenance policy (Fontanini \& Oishi, 2000), as it becomes very expensive, it interrupts the operation of the equipment, and consequently the entire production process. In addition to the cost of maintaining the equipment, there is a high cost in delaying the delivery of orders for materials in the process, operators and machines will be in downtime and production will be lower. Preventive maintenance is an effective way to reduce industrial assets' operation costs (Yang, Ye, Lee, Yang \& Peng, 2019).

Preventive maintenance aims to eliminate or reduce the chances of maintenance failures (Cavalcante, Lopes \& Scarf, 2018). Such maintenance by inspection of the production machine is an important means of controlling the quality of products manufactured (Nourelfath, Nohas \& Ben-Daya, 2016). Preventive maintenance activities, including inspections, repairs, replacements, and routine services are of great importance for a majority of industrial systems as they can mitigate the risk of unexpected failures that may cause tremendous economic losses (Yang et al., 2018). This maintenance is planned to avoid emergency interruptions. The benefits resulting from a preventive maintenance program, well planned and implemented, are several. However, for a program partially implemented, there are few benefits and they result in a bad investment.

\subsection{Predictive maintenance}

Predictive maintenance is the assessment or control of physical changes to facilities, preventing and anticipating failures and taking appropriate remedial measures (Takahashi \& Osada, 1990; Jain, Bhatti \& Singh, 2014). "Predictive maintenance is the periodic measurement and trend of the process or parameters of the machines in order to predict the failures before they occur" (Robinson \& Ginder, 1995, p.28). Predictive maintenance of the equipment must include a periodic inspection to detect and adopt appropriate measures against harmful conditions, which may result in abrupt failures or deterioration in the functioning and quality of the product (He, $\mathrm{Gu}$, Chen, \& Han, 2017). It is extremely important that the sources of problems be eliminated, adjustments be made or recovery measures be taken while the problems are still at an early stage. Therefore, the objective of predictive maintenance is based on economic measures against equipment deterioration. There are three types of measures to prevent equipment from deteriorating. The first is through daily maintenance, the second is the use of predictive techniques and the third through repairs and adjustments (Takahashi \& Osada, 1990). The scope of Predictive Maintenance planning covers all the aspects of Predictive Maintenance that are to be integrated with planning in order to aid decision-making, in the cases of actions to be taken and the performance of the system to be monitored and improved (Basri, Razak, Ab-Samat, \& Kamaruddin, 2017).

By detecting the physical phenomena presented, it will be possible to diagnose the situation in which equipment is found, i.e., it anticipates the expected life of important parts and components with inspections, aiming at the maximum use of these elements for the longest possible time. Among these physical phenomena are analysis of vibration, temperature, pressures, tensions, wear and tear, deterioration, alignment, and corrosion. By investigating all equipment's functions and structures, the best period for maintenance is determined, reducing the impact on production.

\subsection{Total productive maintenance}

"It is a full maintenance system, which has as its fundamental objective the maximization of the operational performance of the machines, generating products with the right quality at the right time" (Nakajima, 1989, p.23). Total Productive Maintenance (TPM) consists of activities with total involvement of employees with the company and is among the most effective methods to transform a factory into an operation with equipmentoriented management. It aims to maximize the use of equipment in the production line (Chan, Lau, Chan \& Kong, 2005; Ahmed, Hassan \& Taha, 2005; Chakravorty, 2011; Suzuki, 1992; Sharma \& Bhardwaj, 2012; Morales Mendez \& Rodriguez, 2017; Filscha, Meilily \& Hendy, 2019; Hooi \& Leong, 2017).

Total Productive Maintenance has had a major impact on financial results, promoting a significant improvement in capacity, reducing not only maintenance costs, but also global operating costs (Aspinwall \& Elgharib, 2013). Wakjira \& Singh (2012) conclude that the implementation of TPM in any organization increases equipment's overall efficiency, increasing availability of equipment, reducing rework, rejections, and the overall improvement in the productivity of a company.

Total Productive Maintenance originally comes from Japan and focuses on solving maintenance problems using the quality circle method. Some of the advantages of implementing TPM in an organization are a better understanding of equipment performance, improved teamwork, a less contradictory approach 
between production and maintenance (Garg \& Deshmukh, 2006). The first requirement for this transformation of the company is that all people, including senior management, supervisors and operators, direct their attention to all components of the factory - molds, installations, tools, industrial instruments, sensors, recognizing the importance and value of equipment-oriented administration (Takahashi \& Osada, 1990). The main objective of TPM is to increase maximum efficiency through total employee involvement, which includes the use of autonomous maintenance by operators, small groups of activities to improve equipment safety, sustainability, and productivity (Chen, 1994; Suzuki, 1992).

There are eight main pillars to TPM including autonomous maintenance, planned maintenance, quality maintenance, focused improvement, equipment management, training and education, environmental health and safety, and administration (Agustiady \& Cudney, 2018). Training practice for operators and maintenance personnel is the basis of TPM. According to Shirose (1992), the purpose of autonomous maintenance is to teach operators how to keep their equipment in perfect condition, through daily checks, lubrication, replacement of parts, repairs, accurate check ups and other tasks. In TPM, human participation is the basis for its development and effective search for results, which aims to reduce equipment failures.

\subsection{The limited perception of human beings in the detection of failures}

Any production system depends on the reliability of the equipment, which is accompanied by the human being. This reliability only happens when the human being is motivated to find out everything that happens in his equipment. Motivation is related to human behaviour (Kanfer, Frese, \& Johnson, 2017). Keeping the human being motivated to perform his/her role is extremely difficult, considering that behaviors aim to achieve goals and are oriented according to the needs that people face, i.e., the work performance of each one depends not only on the ability, but also on the willingness to perform a certain task. It is necessary to understand the motivators of the human being within the organization in order to obtain the quality of the service performed.

The automation of the system, i.e., the implementation of the Just-In-Time Maintenance Program, makes it possible for the faults to be detected in advance, repairs to be performed at the best moment, while the limited human capacity to detect faults might increase the number of errors. Despite the limitations of human beings, they can develop or perform various tasks, but with the Just-In-Time Maintenance Program's implementation, these limitations will be overcome. Human errors contribute to more than three quarters of failures during the life of the equipment. People with the necessary competence and motivation are the backbone of reliable maintenance systems (Narayan, 2012; Juran, 1988; Jordan, 1996).

\subsection{Just-In-Time Maintenance Program}

The demand for equipment control technologies aimed at production stability and product improvement is intensifying with technological advances, as well as with the development of continuous processes and automation in several areas in the production process (Fontanini \& Oishi, 2000). Under this perspective, the Just-In-Time Maintenance Program keeps maintenance costs to a minimum. The Just-In-Time Maintenance Program consists of an integrated system for monitoring physical phenomena through sensors in the equipment and diagnosis center, which receives signals from these sensors, predicting failures that can happen in real time (Fontanini \& Oishi, 2000).

This system enables the operator to know in advance what may happen, anticipating the necessary measures regarding the acquisition of parts, repairs, and personnel allocation, among others. The necessary downtime will be compatible or re-adapted to the production plan so that the delivery deadlines of products should be met. At the same time, the cost of maintenance will be drastically reduced so as to minimize undesirable downtime. In order to implement the Just-In-Time Maintenance Program there is a necessity for a structured system with sensors in each of the monitored equipment, together with a diagnostic system, to operate in real time.

Characteristics of the Just-In-Time Maintenance Program (Fontanini \& Oishi, 2000):

1. Implementation of the structured system covering the management system (Production Control, Maintenance Control).

2. Implementation of the equipment control system in real time, interconnected to a large network.

3. Implementation of the equipment control system interconnected with the real-time diagnosis system.

4. Advance (innovation) of TBM - Time Based Maintenance for MOC - Maintenance Based on Operating Conditions.

5. Implementation of the proper service to different and real needs, covering from isolated sensors to a total structured system. 
The implementation of the Just-In-Time Maintenance Program is justified for the companies with a continuous production process. In case of companies that work with an intermittent production system, the equipment maintenance can be carried out when the equipment is not in production. The production system was the main reason for choosing this agribusiness for the study, as it is a continuous production system. There is no daily downtime for maintenance to be performed. This agribusiness's general maintenance is carried out once a year, usually at the beginning of January.

Table 1: Diagnosis methods applied to equipment and their contents:

\begin{tabular}{|c|c|c|}
\hline Methodology & Equipment & Diagnose Content \\
\hline $\begin{array}{l}\text { 1.Vibration } \\
\text { diagnosis }\end{array}$ & $\begin{array}{l}\text { Pumps, Engines, } \\
\text { Blowers, Rollers }\end{array}$ & $\begin{array}{l}\text { Bearings (bearings, inner and outer rings, poor } \\
\text { lubrication), bending of shafts, wear by deviation, } \\
\text { inadequate alignment, gears (lack of cogs, } \\
\text { scratches), base (lack of resistance, deviations), } \\
\text { cavitation. }\end{array}$ \\
\hline $\begin{array}{l}\text { 2.Positioning } \\
\text { Change Diagnosis }\end{array}$ & Turbines, Pumps & $\begin{array}{l}\text { Warping of axes, wear by deviation, base (lack of } \\
\text { resistance), deviations, resonance. }\end{array}$ \\
\hline $\begin{array}{l}\text { 3.Temperature } \\
\text { Diagnosis }\end{array}$ & $\begin{array}{c}\text { Pumps, engines, } \\
\text { Refrigeration Equipment }\end{array}$ & $\begin{array}{l}\text { Poor axle lubrication, inadequate wire winding, } \\
\text { overload, lack of refrigeration. }\end{array}$ \\
\hline $\begin{array}{l}\text { 4. Acoustic } \\
\text { Diagnosis }\end{array}$ & Engines, blowers & Abnormal friction noise, Propeller failure, Unbalance. \\
\hline $\begin{array}{l}\text { 5. Aeration } \\
\text { Diagnosis }\end{array}$ & Pumps, Pipeline, Valve & Cavitation, leakage, clogging. \\
\hline 6. Torque Diagnosis & $\begin{array}{l}\text { Motors, Rollers, } \\
\text { Reducers }\end{array}$ & Shafts, locking pins. \\
\hline $\begin{array}{l}\text { 7. Diagnosis of } \\
\text { Electric Currents }\end{array}$ & $\begin{array}{c}\text { Engines, Incrustation } \\
\text { cleaners, Conveyor } \\
\text { belts }\end{array}$ & $\begin{array}{l}\text { Dirt penetration, abnormal loads, damaged } \\
\text { transmission chains. }\end{array}$ \\
\hline $\begin{array}{l}\text { 8. Pressure } \\
\text { Diagnosis }\end{array}$ & $\begin{array}{c}\text { Pump, Pipeline, Grease } \\
\text { Pipe, Refrigeration } \\
\text { Equipment }\end{array}$ & Pipeline leakage, valve failures \\
\hline
\end{tabular}

Fontanini \& Oishi, (2000).

\section{Methodology}

The hypothesis that guided this study is that the existing maintenance systems are not effective, from the point of view that unscheduled downtimes continue to occur mainly due to the participation of human beings in the processes. All operational processes involve some degree of human participation. However, human performance is subject to several errors due to inadvertence, lack of techniques and trends. "Most of the time, we forget that people cannot concentrate too much, or for a long time on complex tasks. Therefore, it is important to understand that people are prone to accidents and tend to make mistakes" (Osada, 1992, p.9).

Maintenance has been shown, in most cases, to be inefficient, causing problems due to the replacement of parts being carried out through the estimate of equipment lifetime, i.e., time-based maintenance (Fontanini \& Oishi, 2000; Oishi \& Fontanini, 1997).

As the exchange of parts is carried out considering its lifetime, a part can be replaced without defects, generating replacement cost, in addition to the inconvenience of equipment shutdown, causing production problems. The failures are not self-announcing but should be identified by inspections; a cost is introduced for system inactivity (de Jonge, Teunter \& Tinga, 2017). This research does not focus on showing the inefficiency of Scheduled Maintenance, as it is a time-based maintenance. The objective is to show that the Just-In-Time Maintenance Program can bring superior results for industries that operate with continuous production systems. The choice of the company participating in the research was chosen because of its continuous production process.

The researched company has a continuous production process, and the Just-In-Time Maintenance Program can bring substantial economic and technical advantage, through the increase of revenue with the reduction of downtime and the reduction of the number of people involved in the maintenance. Any unscheduled 
downtime will result in production interruptions. This is a Japanese multinational company that operates in the food segment and, in the early 1990s, was one of the first industries in Brazil to implement Total Productive Maintenance. A non-probabilistic sample was used in this research for convenience, for the reason that the company has released access to internal data. The information collected from the company regarding selling price, raw material cost, electricity cost, and total maintenance expenses are from the year 2020. A mathematical model was created to estimate variations in the company's productivity and the consequent financial impacts. This research is designed as a case study, as it is carried out within a single organization.

\section{Simulation of the Implementation of Just-In-Time Maintenance Program in a Company in the Agribusiness Sector}

A simulation was made using the data of the researched company whose products are destined for both the domestic and foreign markets. After the implementation of the Just-In-Time Maintenance Program in the researched company a 40\% reduction in accidental stops, in personnel involved in maintenance and in the cost of maintenance was estimated. In contrast, in Japan, with the use of a very similar system, this index is $50 \%$. In Brazil, it is possible to reach higher rates than the one used for the simulation of Just-In-Time Maintenance Program implementation. This is the result of the scheduled maintenance being at a stage well below to the maintenance performed in Japan (where a similar system has already been implemented).

\subsection{Mathematical model}

A mathematical model is a simplified representation of a reality's behaviour, expressed in the form of mathematical equations to simulate that reality. In order to be able to evaluate the results of the implementation of a program that will reduce downtime, in continuous production processes, a mathematical model was developed that estimates variations in the company's productivity and the consequent financial impacts. The results, operational and financial, of the model allow for the assessment of the feasibility of implementing each of these programs.

Figure 1 represents the company's monthly productions, in the time interval $H$, for two situations: (i) $Q_{1}$, before the implementation of Just-In-Time Maintenance Program; (ii) $Q_{2}$, after the implementation of Just-InTime Maintenance Program.
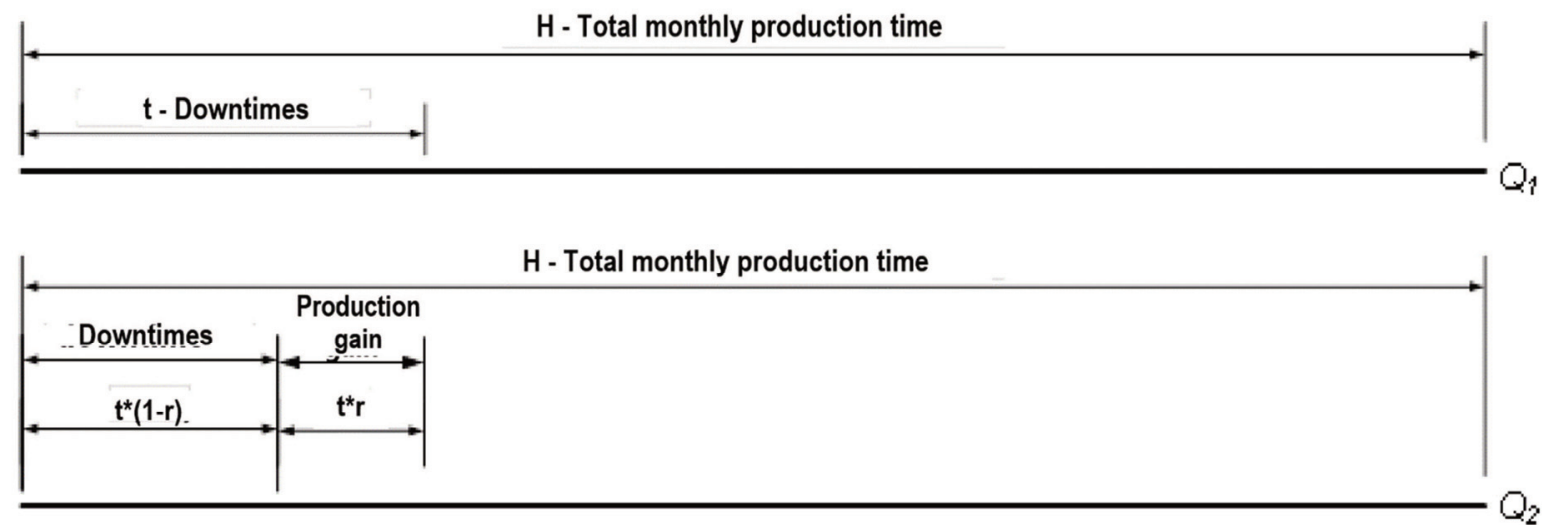

Figure 1: Monthly production $Q_{1}$ and $Q_{2}$ of the company.

In the first timeline of Figure 1, the company's production per unit of time represented in equation 1 is determined before implementing the Just-In-Time Maintenance Program.

$$
Q_{1}=q \times(H-t)
$$

where: $Q_{1}$ is the monthly production produced before the Just-In-Time Maintenance Program, $q$ is the production per unit of time, $H$ is the company's nominal monthly production time, $t$ is the production line downtime before the Just-In-Time Maintenance Program is implemented.

After the implementation of the Just-In-Time Maintenance Program, it is estimated that there will be a gain in $t$ * $r$ production time, which can be seen in the second timeline of Figure 1 . This time gain provides an increase in total production, whose new value is determined by equation 2 . 


$$
Q_{2}=q \times[H-t \times(1-r)]
$$

where: $Q_{2}$ is the monthly quantity produced after the Just-In-Time Maintenance Program, $q$ is the production per unit of time, $H$ is the company's nominal monthly production time, $t$ is the production line downtime before the Just-In-Time Maintenance Program is implemented, $r$ is the percentage of downtime reduction.

The productivity index of the production lines, resulting from the implementation of the Just-In-Time Maintenance Program, is determined by equation 3.

$$
I_{p}=\left(1+\frac{t \times r}{H-t}\right)
$$

where: $I_{p}$ is the productivity index, $H$ is the industry's nominal monthly production time, $t$ is the production line downtime before the Just-In-Time Maintenance Program and $r$ is the factor for reducing downtime after the Just-In-Time Maintenance Program.

As a result of the productivity index, the company will increase production, as shown in equation 4.

$$
Q_{2}=I_{p} \times Q_{1}
$$

where: $Q 2$ is the monthly production after the Just-In-Time Maintenance Program, $Q_{1}$ is the monthly quantity produced before the Just-In-Time Maintenance Program and $I_{p}$ is the productivity index.

The monthly revenue is determined by multiplying the monthly quantity produced by the selling price. The variation of the monthly revenue is given by the difference between the monthly revenue before and after implementing the Just-In-Time Maintenance Program, which is represented by equation 5.

$$
V_{f}=\left(I_{p}-1\right) \times Q_{1} \times p
$$

where: $V_{f}$ is the variation in monthly revenue after the Just-In-Time Maintenance Program, Ip is the productivity index, $Q_{1}$ is the monthly quantity produced before the Just-In-Time Maintenance Program and $p$ is the selling price.

The monthly variable cost is determined by multiplying the unit cost by the monthly quantity produced. The variation in the monthly variable cost is given by the difference between the monthly variable costs before and after the implementation of the Just-In-Time Maintenance Program, represented by equation 6.

$$
V_{c V}=\left(1-I_{p}\right) \times Q_{1} \times C
$$

where: $V c v$ is the variation of the monthly variable cost after the Just-In-Time Maintenance Program, $I_{p}$ is the productivity index, $Q_{1}$ is the monthly quantity produced before the Just-In-Time Maintenance Program and $c$ is the unit cost.

The maintenance cost consists of two installments: (i) fixed cost; (ii) variable maintenance cost. For each type of production processes, it is possible to define a relationship between these costs. From these concepts, the following equations are defined:

$$
C M=C_{F M}+C_{V M}
$$

where: $C M$ is the monthly maintenance cost, $C_{F M}$ is the fixed cost of maintenance and $C_{V M}$ is the variable cost of maintenance

$$
C_{V M}=c_{u m} \times(H-t)
$$

where: $C_{V M}$ is the variable cost of maintenance, $c_{u m}$ is the unit cost of maintenance, $H$ is the industry's nominal monthly production time and $t$ is the production line downtime.

$$
V C M=c_{u m} \times r \times t \times f_{a}
$$

where: VCM is the change in the monthly maintenance cost after the Just-In-Time Maintenance Program, $c_{u m}$ is the unit cost of maintenance, $r$ is the factor for reducing downtime after the Just-In-Time Maintenance 
Program, $t$ is the production line downtime and $f_{a}$ is the percentage of increase in maintenance in relation to unforeseen events.

The gross monthly profit is determined by the difference between monthly revenue and monthly production costs: variable and fixed. The variation of the monthly gross profit is given by the difference between the monthly gross profits before and after the implementation of the Just-In-Time Maintenance Program, represented by equation 10 .

$$
V_{I}=\left(I_{p}-1\right) \times Q_{1} \times(p-c)+V C M
$$

where: $V_{l}$ is the variation of the gross monthly profit after the program, $I_{p}$ is the productivity index, $Q_{1}$ is the monthly quantity produced before the program, $p$ is the selling price, $c$ is the unit cost and VCM is the change in the total monthly maintenance cost after the program.

One aspect that also emerges from the mathematical model is the variation in the contribution margin. When observing equation 10, it is possible to define the contribution margin variation as shown in equation 11.

$$
C_{m v}=\left(I_{p}-1\right) \times(p-c)
$$

where: $C_{m v}$ is the change in the contribution margin after the Just-In-Time Maintenance Program, $I_{p}$ is the productivity index, $p$ is the selling price and $c$ is the unit cost.

Another important aspect is the rate of return on the investment required (Inv) for the implementation of the Just-In-Time Maintenance Program. In order to do that, the determination of i must be considered in equation 12. This value must be higher than the minimum attractiveness rate established for the company's investments.

$$
I n v=\sum_{1}^{n} \frac{(V l-C i n v)}{(1+i)^{n}}
$$

where: Inv is the investment for the implementation of the Just-In-Time Maintenance Program, $V_{l}$ is the change in monthly gross profit after the Just-In-Time Maintenance Program, Cinv is the monthly cost for maintaining the Just-In-Time Maintenance Program and $n$ is the number of months corresponding to the lifetime of the Just-In-Time Maintenance Program.

$\mathrm{i}$ is the internal monthly rate of return on investment.

\subsection{Implementation of the Just-In-Time Maintenance Program in a company in the agricultural sector}

In order to analyze the impact of implementing a program to reduce downtime in companies with continuous production, the following assumptions were considered:

- Agro-industrial company, with total production time equal to 720 hours / month, corresponding to 30 days of operation 24 hours a day.

- On average, this company's monthly downtime is 20 hours. Its average monthly production is $1850 \mathrm{t}$.

- The maintenance program considered is the Just-In-Time Maintenance Program. This program has achieved excellent results in Japan. The percentage of downtime reduction in Japanese companies is $50 \%$. For this study, due to the characteristics of the company's organizational culture in question, the reduction percentage considered was $40 \%$.

Other relevant data obtained in the studied company are the following:

- The selling price of the product is US $\$ 6,000$ per ton.

- The cost of raw material per ton of finished product is US $\$ 3,250$.

- The cost of electricity per ton of finished product is US $\$ 950.00$.

- The total monthly expenditure on maintenance is US $\$ 370,000,23 \%$ of which is fixed (US $\$ 85,000$ ).

The remaining $77 \%$ (US $\$ 285,000$ ) varies, depending on the production downtime.

- The percentage of increase in the unit cost of maintenance due to unforeseen factors is $30 \%$.

The use of the mathematical model in the company, whose operational and financial characteristics are described in the previous paragraphs, results in the values that are embodied in Table 1. 
Table 2: Result of using the mathematical model in the company.

\begin{tabular}{|l|c|c|c|c|}
\hline \multicolumn{1}{|c|}{ Variable } & $\begin{array}{c}\text { Mathematical } \\
\text { model }\end{array}$ & Variation & $\begin{array}{c}\text { Before } \\
\text { JUST-IN-TIME } \\
\text { MAINTENANCE } \\
\text { PROGRAM }\end{array}$ & $\begin{array}{c}\text { After } \\
\text { JUST-IN-TIME } \\
\text { MAINTENANCE } \\
\text { PROGRAM }\end{array}$ \\
\hline Productivity Index & Equation 3 & 0.01143 & 1.00000 & 1.01143 \\
Monthly Production (t) & Equation 4 & 17.14 & 1,500 & $1,517.14$ \\
Monthly Billing (US\$) & Equation 5 & 102,857 & $9,000,000$ & $9,102,857$ \\
Monthly Cost (US\$) & Equation 6 & 31,200 & $2,730,000$ & $2,761,200$ \\
Maintenance Cost (US\$) & Equation 7 & 185 & 80,000 & 79,814 \\
Monthly Profit (US\$) & Equation 10 & 71,472 & $6,190,000$ & $6,261,472$ \\
Contribution Margin (US\$) & Equation 11 & 47 & 4,180 & 4,227 \\
\hline
\end{tabular}

Source: Authors calculations

Looking at Table 1, it is possible to conclude that the implementation of the Just-In-Time Maintenance Program allows for an increase in productivity of $1.14 \%$, which is reflected in the following operational and financial parameters of the company:

- Increase of 17.14 tons in monthly production;

- Increase of US \$102,857 in monthly invoicing;

- Variable cost increase of US \$31,200;

- Reduction in total maintenance cost is US \$ 185.00 per month, which provides an increase in monthly profit of US \$ 71.472;

- Increase in the monthly contribution margin of US $\$ 47,77$.

Adding these values and considering that the investment required for the implementation of the Just-In-Time Maintenance Program is in the order of $U \$ 700,000$, the estimated monthly rate of return, for a period of 12 months (1 year), is $1.7 \%$. The estimated payback for the project is 9.8 months.

\section{Results and Discussion}

In an attempt to solve the flaws detected in the company regarding equipment maintenance, it was shown how the Just-In-Time Maintenance Program could solve such deficiencies, showing the great utility and performance of the implementation of this maintenance program. The benefit was estimated that could be obtained with the adoption of the Just-In-Time Maintenance Program, with data provided by the observed company based on three indicators - unscheduled downtime, man-hours spent on maintenance and maintenance costs, knowing that, with the implementation of the Just-In-Time Maintenance Program in Japanese companies has resulted in a $50 \%$ reduction in these indexes. This would allow for the hypothesis that there is a potential for reduction of at least $40 \%$ - an index used for testing - in Brazilian companies, especially in agri industries. Although Japanese companies achieved an improved level of scheduled maintenance, there was a $50 \%$ drop in the rates of unscheduled downtime, staffing and maintenance costs with the introduction of a similar maintenance program in Japan. In Brazil, where scheduled maintenance was shown to be at a precarious stage, in comparison with what was observed in Japan, the introduction of the Just-In-Time Maintenance Program in the researched company would bring an even greater drop of $40 \%$.

In order to estimate the variation in profit with the introduction of the Just-In-Time Maintenance Program, it was necessary to calculate the variation in revenue, production cost and maintenance cost, reaching the result sought, not considering the reduction in the cost of spare parts and components. The raw material, electric energy and the labour employed in the production were considered variable costs and other costs as constant, as well as the cost per man-hour. With the reduction in the cost of parts or components for replacement, if considered, the variation in profit would be even greater.

As a result of the simulation of the implementation of the Just-In-Time Maintenance Program in the researched company, the monthly production which was 1,500 tons/month and, with the reduction of unscheduled downtime by $40 \%$, increased in 8 hours/month in the productive time, increasing the monthly production to 1.517 tons/month. This resulted in an increase in revenue of approximately US $\$ 102,857$. 
The increase in the cost of raw materials and electricity due to the increase in production time corresponded to approximately US $\$ 30,940$. The reduction in the cost of labour involved in maintenance, due to the decrease in downtime by $40 \%$, was approximately US $\$ 13.914$. This is due to the following considerations:

- A portion of the cost of labour applied to maintenance corresponding to unscheduled downtime would be reduced by a proportion of $40 \%$.

- A portion of the remainder of the maintenance labour cost would fall in proportion to the rate of reduction in unexpected downtime. Another part would be semi-variable and yet another, invariable. Thus, the increase in the estimated profit with the total maintenance cost reduction is US $\$ 71.472$ / month.

\section{Final Considerations}

A research was presented in this article identifying the potential for the implementation of the Just-In-Time Maintenance Program with great technical and economic benefit in a company in the agricultural sector in the state of Paraná. Simulating the use of this system and proving that in addition to meeting the needs regarding the problems generated in the use of scheduled maintenance, it is possible through the Just-In-Time Maintenance Program to know the best time to replace parts, thus reducing maintenance costs, as evidenced in the presentation of the results, and in addition to increased production.

In the researched company, with a significant number of unscheduled downtime, the implementation of this program results in the reduction of unscheduled downtime, increase in the system's availability for production, proving the existence of a great potential for the implementation of this system in these industries. It is important to highlight that the types of maintenance that exist, due to their characteristics, are unable to reduce or minimize errors caused by the limited capacity of the human being, which with the Just-In-Time Maintenance Program becomes possible.

The Just-In-Time Maintenance Program also brings the possibility of knowing the best time to replace parts, reducing maintenance costs, as evidenced in the presentation of the results. The implementation of the Just-In-Time Maintenance Program results in a consistent increase in productivity and quality due to the reduction of unforeseen downtime. The profit obtained from such reductions makes this program a valuable agent of change.

This maintenance program can also be used in other industries that have a continuous production process. The implementation of the Just-In-Time Maintenance Program makes all production planning easier, in addition to reducing unscheduled downtime. It is possible to replace parts at the necessary time, avoiding investments to keep parts in stock and, above all, aligning the production area, maintenance and production, preventing these areas from coming into conflict due to lack of planning or inadequate planning. The production line's availability increases due to the reduction of unscheduled stops, consequently reducing costs, producing more and at higher quality, making the industry more competitive. This is what distinguishes the Just-In-Time Maintenance Program.

Currently, this agribusiness uses Total Productive Maintenance to manage the maintenance of its equipment. Still, based on the results obtained in this article, the expectation is that it can take another look at the Just-In-Time Maintenance Program, considering the possibility of its implementation in the near future. Another benefit with the implementation of the Just-In-Time Maintenance Program, not explored in this research, one that should be considered as suggestion for future research, would be in relation to supply chain management, in which the researched company could have many advantages like being a focal company, or as a supply chain player.

By reducing unscheduled downtimes, it would be possible to improve the customer service extraordinarily, since the delivery would be made within the agreed term, guaranteed reduction in the product's price, the decline in production costs, and finally, the quality assured product.

\section{REFERENCES}

[1] Agustiady, T. K., \& Cudney, E. A. (2018). Total productive maintenance. Total Quality Management \& Business Excellence, 1-8. DOI:10.1080/14783363.2018.1438843.

[2] Ahuja, I.P.S.; Khamba, J. S., (2008). Total productive maintenance: literature review and directions. International Journal of Quality \& Reliability Management, 25(7), 709 - $756 . \quad$ DOI: $10.1108 / 02656710810890890$

[3] Ahmed, S., Hassan, M. H., \& Taha, Z. (2005). TPM can go beyond maintenance: excerpt from a case implementation. Journal of Quality in Maintenance Engineering, 11(1), 19-42. DOI: $10.1108 / 13552510510589352$

[4] Aspinwall, E., \& Elgharib, M. (2013). TPM implementation in large and medium size organizations. Journal of Manufacturing Technology Management. 24(5), 688-710. DOI: 10.1108/17410381311327972 
[5] Bartz, T., Siluk, J.C. M., \& Bartz, A.P.B. (2014). Improvement of industrial performance with TPM implementation. Journal of Quality in Maintenance Engineering, 20(1), 2-19.

[6] Basri, E. I., Razak, I. H. A., Ab-Samat, H., \& Kamaruddin, S. (2017). Preventive maintenance (PM) planning: a review. Journal of Quality in Maintenance Engineering. DOI: 10.1108/JQME-04-2016-0014

[7] Cavalcante, C. A., Lopes, R. S., \& Scarf, P. A. (2018). A general inspection and opportunistic replacement policy for one-component systems of variable quality. European Journal of Operational Research, 266(3), 911-919. DOI: 10.1016/j.ejor.2017.10.032

[8] Chakravorty, S.K. (2011). Total Productive Maintenance-A Dynamic Enabler to Manage Productivity in a Manufacturing Organization. Productivity, 52(2/3), 97.

[9] Chan, F.T.S., Lau, H.C.W., R.W.L., Chan, H.K., Kong, S. (2005). Implementation of total productive maintenance: A case study. International journal of production economics, 95(1), 71-94. DOI: 10.1016/j.ijpe.2003.10.021

[10] Chen, F. (1994). Benchmarking: preventive maintenance practices at Japanese transplants. International Journal of Quality \& Reliability Management, 11(8), 19-26. DOI: 10.1108/02656719410070084

[11] De Jonge, B., Teunter, R., \& Tinga, T. (2017). The influence of practical factors on the benefits of condition-based maintenance over time-based maintenance. Reliability engineering \& system safety, 158, 21-30. DOI: 10.1016/j.ress.2016.10.002

[12] De Marco, A., \& Mangano, G. (2011). Relationship between logistic service and maintenance costs of warehouses. Facilities, 29, 411-421. DOI: 10.1108/02632771111146323

[13] Filscha, N., Meilily, A., \& Hendy, T. (2019). Total productive maintenance policy to increase effectiveness and maintenance performance using overall equipment effectiveness. Journal of Applied Research on Industrial Engineering, 6 (3), 184-199.

[14] Fontanini, C.A.C, Oishi, M, (2000). MJIT - Manutenção just in time: manutenção otimizante realizada no tempo exato baseado em condições operacionais. In: III Simpósio de Administração da Produção, Logística e Operações Internacionais. São Paulo: FGV.

[15] Garg, A., Deshmukh, S.G., (2006). Applications and case studies maintenance management: literature review and directions. Journal of Quality in Maintenance Engineering, 12(3), 205-238. DOI: $10.1108 / 13552510610685075$

[16] He, Y., Gu, C., Chen, Z., \& Han, X. (2017). Integrated predictive maintenance strategy for manufacturing systems by combining quality control and mission reliability analysis. International Journal of Production Research, 55(19), 5841-5862. DOI: 10.1080/00207543.2017.1346843

[17] Hooi, L. W., \& Leong, T. Y. (2017). Total productive maintenance and manufacturing performance improvement. Journal of quality in maintenance engineering. 23(1),2-21. DOI: 10.1108/JQME-07-20150033

[18] Jain, A., Bhatti, R., Singh, H., (2014). Total productive maintenance (TPM) implementation practice: a literature review and directions. International Journal of Lean Six Sigma, 5(3), 293-323. DOI:10.1108/IJLSS-06-2013-0032

[19] Jimenez, V.J., Bouhmala, N., Gausdal, A.H. (2020). Developing a predictive maintenance model for vessel machinery. Journal of Ocean Engineering and Science 5, 358-386. DOI: 10.1016/j.joes.2020.03.003

[20] Jordan, Steve, (1996). Man and machine in harmony? Assembly Automation, vol.16, n.1, p.13-17.

[21] Juran, J.M. Juran on Planning for Quality, (1988). Ann Arbor, Michigan: Free Press.

[22] Kanfer, R., Frese, M., \& Johnson, R. E. (2017). Motivation related to work: A century of progress. Journal of Applied Psychology, 102(3), 338. DOI: 10.1037/apl0000133

[23] Kaur, M., Singh, K., Ahuja, S., (2013). An evaluation of the synergic implementation of TQM and TPM paradigms on business performance. International Journal of Productivity and Performance Management, 62 (1), 66-84. DOI: 10.1108/17410401311285309

[24] Morales Mendez, J.D., Rodriguez, R.S. Total productive maintenance (TPM) as a tool for improving productivity: a case study of application in the bottleneck of an auto-parts machining line, (2017). Int J Adv Manuf Technol 92, 1013-1026. DOI:10.1007/s00170-017-0052-4

[25] Nakajima, S., (1989). TPM development program: implementing total productive maintenance. Portland, Oregon: Productivity Press.

[26] Narayan, V., (2012). Business performance and maintenance: how are safety, quality, reliability, productivity and maintenance related? Journal of Quality in Maintenance Engineering, 18(2), 183-195. DOI: $10.1108 / 13552511211244210$

[27] Nourelfath, M., Nohas, N., Ben-daya, M., (2018). Integrated preventive maintenance and production decisions for imperfect processes. Reliability Engineering \& System Safety, 148, 21-31. DOI: 10.1016/j.ress.2015.11.015

[28] Oishi, M.; Fontanini, C. A. C. (1997). MJIT - Manutenção por Just in Time: manutenção otimizante realizada no tempo exato baseado em condições operacionais. Revista Produção [online], vol.7, n.1, pages $75-83$ 
[29] Osada, T., (1992). Housekeeping, 5s, seiri, seiton, seiketsu, shitsuke. São Paulo: Instituto Iman.

[30] Robinson, C.J., Ginder, A.P., (1995). Implementing TPM: the North American experience. Portland, Oregon: Productivity Press.

[31] Ruschel, E., Santos, E. A. P., \& Loures, E. D. F. R. (2017). Industrial maintenance decision-making: A systematic literature review. Journal of Manufacturing Systems, 45, 180-194. DOI: 10.1016/j.jmsy.2017.09.003

[32] Sharma, A. K., \& Shudhanshu, A. B. (2012). Manufacturing performance and evolution of TPM. International journal of engineering science and technology, 4(03), 854-866.

[33] Shirose, K., (1992). TPM for workshop leaders. Portland, Oregon: Productivity Press.

[34] Singh, B.J.,Khanduja, D., (2010). SMED: for quick changeovers in foundry SMEs. The International Journal of Productivity and Performance Management, 59(1), 98-116. DOI; 10.1108/17410401011006130

[35] Suzuki, T., (1992). New directions for TPM. Massachusetts: Productivity Press, Inc.

[36] Takahashi, Y., Osada, T., (1990). TPM-Total productive maintenance. Asian Productivity Organization, Tokyo.

[37] Teixeira, H. N., Lopes, I., \& Braga, A. C. (2020). Condition-based maintenance implementation: a literature review. Procedia Manufacturing, 51, 228-235. DOI: 10.1016/j.promfg.2020.10.033

[38] Velmurugan, R.S., Dhingra, T., (2015). Maintenance strategy selection and its impact in maintenance function: a conceptual framework. International Journal of Operations \& Production Management, 35(12), 1622-1661. DOI: 10.1108/IJOPM-01-2014-0028

[39] Wakjira, W., Singh, A.P., (2012). Total productive maintenance: a case study in manufacturing industry. Global Journal of Researches in Engineering, 12(1-G).

[40] Yang, L., Ye, Z. S., Lee, C. G., Yang, S. F., \& Peng, R. (2019). A two-phase preventive maintenance policy considering imperfect repair and postponed replacement. European Journal of Operational Research, 274(3), 966-977. DOI: 10.1016/j.ejor.2018.10.049

[41] Yang, L., Zhao, Y., Peng, R., \& Ma, X. (2018). Hybrid preventive maintenance of competing failures under random environment. Reliability Engineering \& System Safety, 174, 130-140. DOI: 10.1016/j.ress.2018.02.017

Received: 2020-11-20 Revisions requested: 2021-01-31 Revised: 2021-02-08 (2 revisions) Accepted: 2021-02-12

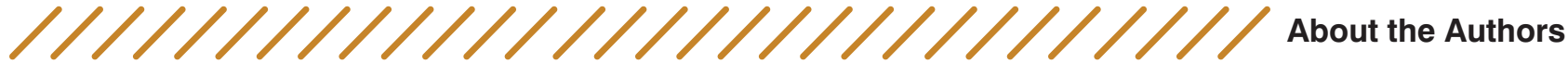

Carlos Augusto Candêo Fontanini Pontifical Catholic University of Parana, Brazil c.fontanini@pucpr.br

Carlos Augusto Candêo Fontanini, Ph.D. is an Assistant Professor at the Pontifical Catholic University of Parana, Business School. He is the coordinator of the Accreditation Center, and International Agent - Business School, guest professor at Beijing Normal University - China and IAE Pau-Bayonne École Universitaire de Management - France. He is also a Vice President of Association of BRICS Business School (ABBS) - Brazil. He is a consultant for public and private organizations. His research areas of interest include production \& operations and supply chain management.

\section{Dewev Wollmann Pontifical Catholic University of Parana, Brazil dewey.wollmann@pucpr.br}

Dewey Wollmann, Dr.Eng. is a full professor at the Pontifical Catholic University of Parana, Polytechnic School. He is a professor in the undergraduate courses in Civil Engineering, Industrial Engineering, Software Engineering and Computer Science. $\mathrm{He}$ is a consultant for public and private organizations. His research areas of interest

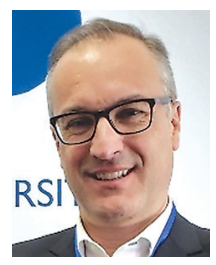
include strategic decision making using mathematical models

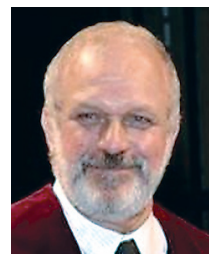
(optimization, multi-criteria and simulation). 